\title{
Interferon-induced protein 16 expression in colorectal cancer and its correlation with proliferation and immune signature markers
}

\author{
YUNLIAN ZOU $^{1}$, JINPING ZHANG ${ }^{2}$, LICHEN ZHANG $^{3}$ and XINMIN YAN ${ }^{1}$ \\ ${ }^{1}$ Faculty of Environmental Science and Engineering, Kunming University of Science and Technology, Kunming, \\ Yunnan 650500; ${ }^{2}$ Institute of Medical Sciences, Yunnan Blood Disease Clinical Medical Center, \\ The First People's Hospital of Yunnan Province, Affiliated Hospital of Kunming University of \\ Science and Technology, Kunming, Yunnan 650032; ${ }^{3}$ Medical Faculty, Kunming University of \\ Science and Technology, Kunming, Yunnan 650500, P.R. China
}

Received January 18, 2021; Accepted June 16, 2021

DOI: $10.3892 / \mathrm{ol} .2021 .12948$

\begin{abstract}
Interferon-induced protein 16 (IFI16) is important for innate immune recognition of foreign/damaged DNA. Abnormal IFI16 expression is closely related to the occurrence of multiple malignant tumours, but its expression pattern in colorectal cancer (CRC) remains unclear. The present study aimed to investigated IFI16 expression and association with cell proliferation in CRC tissues and adjacent normal tissues. A multiplex immunofluorescence panel of antibodies against IFI16, Ki-67 and phosphorylated (p)-ERK1/2 was applied to assess a tissue microarray (TMA). The TMA included 77 CRC samples and 74 normal adjacent tissue samples which were collected from The First People's Hospital of Yunnan Province (Kunming, China) (3 paracancerous tissues were lost because of repeated cutting). Immunohistochemistry was used to detect $\mathrm{CD}^{+}$tumour-infiltrating lymphocyte (TIL) abundance and programmed death-ligand 1 (PD-L1) expression in cancer tissues. The present study demonstrated that IFI16 localized to the nucleus of CRC cells. Although IFI16 was weakly expressed in normal mucosal epithelial cells, absent to strong expression was detectable in different patients with CRC. Typically, IFI16 was not co-localized with Ki-67 within CRC cells. The multiplex immunofluorescence data demonstrated that the proportion of IFI $16-/ \mathrm{Ki}-67^{+}$cells from CRC tissues was $57.13 \%$; however, that of IFI $16^{+} / \mathrm{Ki}-67^{+}$cells was $1.50 \%$. The IFI $16^{-} / \mathrm{Ki}-67^{+}$phenotype was significantly positively associated with the tumor-node-metastasis stage and was marginally significantly correlated with lymph node
\end{abstract}

Correspondence to: Professor Xinmin Yan, Faculty of Environmental Science and Engineering, Kunming University of Science and Technology, 727 South Jingming Road, Kunming, Yunnan 650500, P.R. China

E-mail: yxmin08@163.com

Key words: colorectal cancer, interferon-induced protein 16, Ki-67, phosphorylated-ERK1/2, CD8 ${ }^{+}$tumour-infiltrating lymphocyte, programmed death-ligand 1 metastasis. p-ERK $1 / 2$ protein was primarily localized to the cytoplasm and cell membrane of CRC cells and sometimes to the nucleus. Although, IFI16 demonstrated a strong correlation with p-ERK1/2, IFI16 did not co-localize with p-ERK1/2 and the proportion of IFI16 and p-ERK1/2 double-negative CRC cells was $84.95 \%$. IFI16 expression displayed no significant association with CD8 ${ }^{+}$TILs or PD-L1. However, a strong positive correlation between CD8 ${ }^{+}$TILs and PD-L1 was observed. High $\mathrm{CD}^{+}$TIL infiltration in CRC tissue was associated with lower lymph node metastasis and tumor-node-metastasis stage. In summary, the results of the present study provided a novel insight for the role of IFI16 in CRC occurrence via the regulation of cancer cell proliferation.

\section{Introduction}

Colorectal cancer (CRC) is the most common malignant tumour. It is estimated that CRC accounts for $\sim 10 \%$ of all new cancer cases and cancer-associated mortalities worldwide each year (1). Due to its insidious onset, $20-22 \%$ of patients with CRC present with metastatic disease at initial diagnosis, and 50-60\% eventually develop metastasis. The 5-year overall survival rate for metastatic CRC is $<14 \%$ (2). In-depth exploration of the mechanism of CRC occurrence and progression is critical for improving existing detection methods and overcoming current treatment limitations.

Interferon-induced protein 16 (IFI16) is a member of the interferon-induced HIN200 gene family. IFI16 was first identified in haematopoietic immune cells and was later found in fibroblasts and epithelial cells derived from various human tissues, such as lymph node, spleen, trachea and skin $(3,4)$. Most HIN200-family proteins contain a homotypic protein-protein interaction PYRIN domain (PYD) region in the N-terminus and this domain can bind to the PYD protein and induce cell apoptosis (5). HIN200-family proteins also share a partially conserved repeat of 200 amino acid residues in the C-terminus by which the protein binds to foreign or damaged double-stranded DNA (dsDNA) to activate the innate immune response and inhibit cells growth $(6,7)$. In addition, IFI16 protein has emerged as an important stimulator of IFN- $\beta$ expression in myeloid and non-myeloid cells (8). IFI16 serves 
a key role in connecting innate immunity and adaptive immunity (7). Hence, IFI16 is an innate immune sensor of foreign or damaged DNA and serves an important role in innate immune responses, cell differentiation and proliferation (9). Abnormal IFI16 expression is closely associated with immune system diseases and the occurrence of various malignant tumours, such as systemic lupus erythematosus and breast cancer $(9,10)$.

IFI16 is upregulated during the onset of cellular senescence in a variety of human cells, such as human fibroblasts and bone and cartilage tumor cells (9-11). IFI16 can interact with $\mathrm{p} 53$, $\mathrm{p}-\mathrm{Rb}$, breast cancer gene 1 (BRCA1) protein, among others, to active p53 target genes, such as the cyclin-dependent kinase inhibitor $\mathrm{p} 21^{\mathrm{WAF} 1 / \mathrm{CIP} 1}$, the inhibitor of cyclin-dependent kinase 4a (p16INK4a), Bax and Human double minute 2 (Hdm2), and inhibit cell growth (10-12). Accordingly, loss of IFI16 expression is associated with immortalization of cells and the development of certain human cancer types, such as breast cancer and prostatic cancer (13-15). However, a few studies have indicated that the involvement of IFI16 in human cancer development varies depending on the cell source and cell content. Cai et al (16) demonstrated that IFI16 promoted cervical cancer progression by upregulating programmed death-ligand 1 (PD-L1) in the immunomicroenvironment through the stimulator of interferon genes-TANK-binding

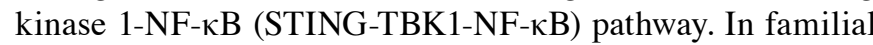
inherited Wilms tumorigenesis, the WT1 gene participates in tumorigenesis by regulating the spatial ectopic nature of IFI16 and thus combines with IFI16 protein to support cell survival (17). The same phenomenon was observed in liver cancer progression (18-20). However, whether IFI16 is involved in the CRC development remains unclear.

In our previous study (21), high-throughput gene expression profiling was applied to assess gene expression characteristics throughout the CRC development process, and the results demonstrated that IFI16 was abnormally highly expressed during the CRC process, which is consistent with the results reported by Yang et al (22). Based on our previous work and review of the current literature, we predicted that IFI16 may serve an important role in CRC occurrence and progression. In the present study, IFI16 expression and its correlation with proliferation and immune signature markers was investigated in CRC tissues and adjacent normal tissues. The findings of the present study suggested that IFI16 takes part in CRC occurrence via regulation of $\mathrm{CRC}$ cell proliferation.

\section{Materials and methods}

Tissue specimens. The human CRC tissue microarray (TMA) was purchased from Shanghai Xinchao Biological Technology Co. Ltd. and contained 77 CRC tissues and adjacent normal tissues obtained by resection between January 2012 and December 2013 from the First People's Hospital of Yunnan Province (Kuming, China). However, 3 adjacent normal tissues were lost due to repeated cutting. The inclusion criteria used were as follows: i) All samples were selected from patients with newly diagnosed CRC who had resection of colorectal tumours without radiation therapy or chemotherapy; and ii) the pathological information of the patients with CRC were complete. The exclusion criteria were as follows: i) Patients aged $<18$ years; ii) patients with chronic diarrhea; and iii) patients who had chemotherapy, radiation therapy or immunotherapy or viral infection, such as Polyomaviruses (23). Among the $77 \mathrm{CRC}$ patients, the median age was 64 years (age range, $42-85$ years), and the average age was $64.34 \pm 12.33$ years. The 77 enrolled patients provided written informed consent and the Ethics Committee of The First People's Hospital of Yunnan Province (Kunming, China) ratified the study (approval no. KHLL-2021-101). TMAs containing the tissue cores were then cut into $4-\mu \mathrm{m}$ sections for immunohistochemistry (IHC) staining. The detailed clinical characteristics of the patients enrolled in this study are summarized in Table I.

Antibodies. In the present study the primary antibodies used were as follows: Rabbit anti-human phosphorylated (p)-ERK monoclonal antibody (1:500; cat. no. cst4370; Cell Signaling Technology Inc.); rabbit anti-human Ki-67 monoclonal antibody (1:500; cat. cst12202; Cell Signaling Technology Inc.); a rabbit anti-human IFI16 monoclonal antibody (immunohistochemistry, 1:1,000; western blotting, 1:1,000, cat. no. cst14970; Cell Signaling Technology Inc.); rabbit anti-human CD8 monoclonal primary antibody (1:50; cat. no. PA067; Suzhou Baidao Medical Technology Co., Ltd.) rabbit anti-human PD-L1 monoclonal antibody (cat. no. GT2280; Gene Tech Biotechnology, Co., Ltd.), rabbit anti- $\beta$-actin polyclonal antibody (1:3,000; cat. no. 14395-1-AP; Proteintech Group, Inc.). Human tonsil, which was purchased from Shanghai Xinchao Biological Technology Co. Ltd. was stained with Ki-67 antibody as a positive control according to the recommendations from the International Ad Hoc Expert Committee (24). Staining of human tonsil slides with isotype control antibody (1:500; Rabbit (DA1E) mAb IgG XP ${ }^{\circledR}$ isotype control; cat. no. cst3900; Cell Signaling Technology Inc.) was performed as negative controls. Human lung tissues were stained with IFI16 and p-ERK1/2 antibodies as positive controls. Staining of human lung slides with isotype control antibody (cat. no. cst3900) was performed as negative controls.

Immunohistochemistry and image analysis. Formalin-fixed paraffin-embedded (FFPE) tissue was cut into 4- $\mu$ m-thick sections and subjected to immunohistochemical analysis. Sections were dewaxed in xylene 3 times for $3 \mathrm{~min}$ each time at room temperature and rehydrated through a series of graded alcohols in distilled water (100, 95 and $70 \%$ ethanol and in distilled water finally). Heat-mediated antigen retrieval was performed in citrate buffer ( $\mathrm{pH}$ 6.0) using microwave treatment. Then, the slides were washed with TBST $(0.05 \%$ Tween-20) buffer and the endogenous peroxidase activities were diminished with $0.3 \% \mathrm{H}_{2} \mathrm{O}_{2}$ for $10 \mathrm{~min}$ at room temperature. Subsequently, blocking of the slices using 10\% goat plasma (cat. no. C0265; Beyotime Institute of Biotechnology) was conducted. Rabbit anti-human CD8 monoclonal primary antibody and rabbit anti-human PD-L1 monoclonal primary antibody were added and incubated with the slides at $4^{\circ} \mathrm{C}$ overnight in a humidified chamber. In all experiments, an isotype control antibody was used as a negative control and no staining was obtained. Detection was performed using the REAL EnVision Detection System (DAB; cat. no. K500711; Dako; Agilent Technologies, Inc.) (25). In brief, the slides which were incubated with primary antibody were wahsed in TBST 3 times for 3 min each time at 
Table I. Clinical characteristics of patients with CRC ( $n=77)$.

\begin{tabular}{lc}
\hline Clinical characteristic & $\mathrm{n}(\%)$ \\
\hline Sex & \\
Male & $42(54.5)$ \\
Female & $35(45.5)$ \\
Age, years & \\
$>55$ & $42(54.5)$ \\
$\leq 55$ & $35(45.5)$ \\
Unknown & - \\
TNM stage & \\
I+II & $44(57.1)$ \\
III+IV & $33(42.9)$ \\
Differentiation & \\
Poorly & $11(14.3)$ \\
Well & $66(85.7)$ \\
Lymph node metastasis & \\
No & $45(58.4)$ \\
Yes & $32(41.6)$ \\
Primary tumor sidedness & \\
Right-sided & $37(48.1)$ \\
Left-sided & $34(44.2)$ \\
Unknown & $6(7.8)$ \\
\hline
\end{tabular}

TNM, tumor-node-metastases; CRC, colorectal cancer.

room temperature. Then incubated the tissues with REAL EnVision Detection System for $1 \mathrm{~h}$ and washed the slides again. Following stained the tissues with DAB for $15 \mathrm{~min}$. Sections were counterstained with haematoxylin and eosin (H\&E) at room temperature for 5 mins and image acquisition was performed using a light microscope (Nikon Corporation) (magnification, $x 100$ ). After the immunostained slides had been reviewed by $\geq 2$ independent pathologists from Shanghai Xinchao Biological Technology Co. Ltd. and consensus was achieved, the specific staining of defined positive and negative cells of CD8 or PD-L1, such as position, localization and cell types was matched with H\&E staining. The percentage of cells with CD8 and PD-L1 expression was recorded as an average fraction of 100 neoplastic cells in every 3 fields, and the intensity of CD8 and PD-L1 staining was graded on a scale of 0 to $3+(0$, absent staining; $1+$, weak staining; $2+$, moderate staining; and $3+$, strong staining). SPSS v.22.0 software (IBM Corp.) was used for statistical analysis.

Multiplexed immunofluorescence (MIF). FFPE TMAs were deparaffinized, rehydrated and subjected to antigen retrieval and diminishment of endogenous peroxidase activities as aforementioned. The primary antibody for p-ERK1/2 was incubated with the TMA for $30 \mathrm{~min}$ in a humidified chamber at room temperature and detection was performed using a Poal ${ }^{\mathrm{TM}}$ Polymer HRP Ms+Rb kit and Opal PPD520 TSA Plus (1:50; cat. no. PPA200, PerkinElmer, Inc.) and were used according to the manufacturer's instructions. Subsequently, the slide was again placed in citrate buffer ( $\mathrm{pH}$ 6.0) for microwave treatment for $15 \mathrm{~min}$. The slide was then incubated with primary antibody targeting IFI16 for $30 \mathrm{~min}$ at room temperature. This was followed by detection using Opal PPD570 TSA Plus (1:50). The slide was placed in citrate buffer ( $\mathrm{pH}$ 6.0) for microwave treatment again. Then, the slide was incubated with primary antibody against $\mathrm{Ki}-67$ for $30 \mathrm{~min}$ at room temperature. Ki-67 was visualized using Opal PPD650 TSA Plus (1:50). The slide was then placed in citrate buffer ( $\mathrm{pH}$ 6.0) and heated via microwave treatment. The nuclei were subsequently visualized with DAPI (Thermo Scientific Inc.) at room temperature for $5 \mathrm{~min}$. The slices were visualized under a PerkinElmer Vectra Polaris ${ }^{\mathrm{TM}}$ fluorescent microscope (Neo Genomics Laboratories) (magnifications, x100 and x400).

Fluorescence signal quantification and image analysis. To obtain multispectral images, the stained slides were scanned using the Vectra System (PerkinElmer, Inc.), which captures the fluorescence spectra at 20-nm wavelength intervals from 420 to $720 \mathrm{~nm}$ with an identical exposure time; the scans were combined to build a single-stack image. Images of unstained sections or single-stained sections were used to deduct the autofluorescence and fluorescein fluorescence observed in tissues. The extracted images were further used to establish a spectral library required for multispectral unmixing using InForm Tissue Finder ${ }^{\mathrm{TM}}$ Advanced image analysis software (PerkinElmer). The InForm Tissue Finder ${ }^{\mathrm{TM}}$ Advanced image analysis software automatically distinguished, the mucosal basal layer cells and the malignant cells from the normal cells based on the atypia of tumour tissue structure and the atypia of tumour cells. The atypia of tumour tissue structure is characterized by a disordered arrangement, direction, cell layers and cell rank order under a low power light microscope (magnification, x100) (26). The atypia of tumour cells usually have features with difference in size, irregular in shape, increasing the karyoplasmic ration and atypical pathologic mitoses under a high-magnification light microscope (magnification, $\mathrm{x} 400)(26)$.

Using this spectral library, reconstructed images of sections with the autofluorescence removed were obtained. Each cell was identified by detecting the nuclear spectral element (DAPI). To define IFI16 ${ }^{+}$and Ki- $67^{+}$tumours, specimens displaying unequivocal nucleus staining were classified as positive. p-ERK1/2 expression that demonstrated a membranous, cytoplasmic or nuclear staining pattern was classified as positive. IFI16, Ki-67 and p-ERK1/2 are reported as normalized fluorescence intensity in tumour and peritumoural tissue segments (Figs. 1 and 2). The proportion of IFI16, Ki-67 and p-ERK1/2 positive tumour cells (TCs) was evaluated as the percentage of total TCs (Fig. 3). The normalized fluorescence intensity was automatically calculated and reported by the InForm image analysis software. In brief, a threshold of positive fluorescence signal was set before the calculation was performed. Then, the fluorescence intensity was divided into 3 levels: An intensity of 1 was defined as a cell-positive signal strength between 1 and 2 times the threshold; an intensity of 2 was defined as a cell-positive signal between 2 and 3 times the threshold; and an intensity of 3 was defined as a cell-positive signal that was more than 3 times the threshold. Following this, the data were automatically calculated and reported by the following formula: Normalized fluorescence intensity 
A

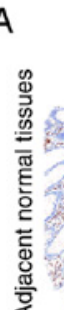

क

$\mathrm{IFI} 16$

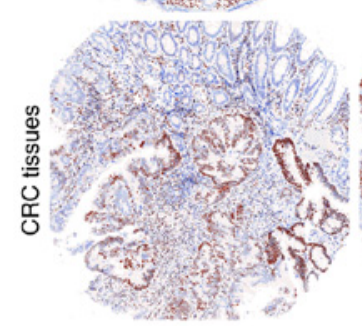

B

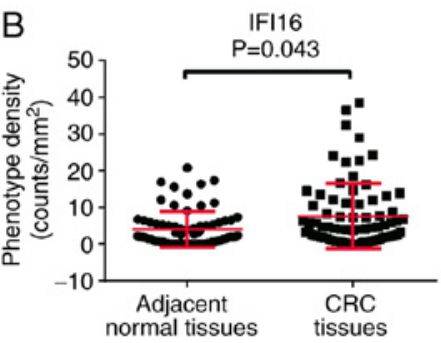

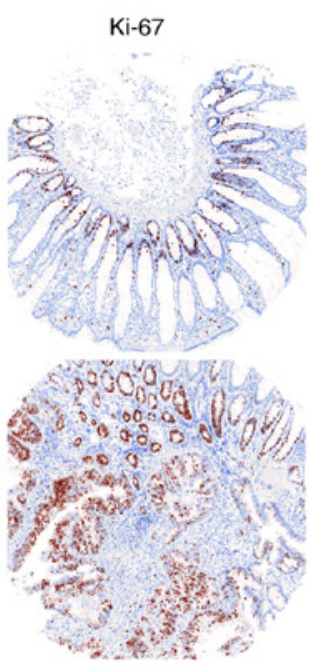

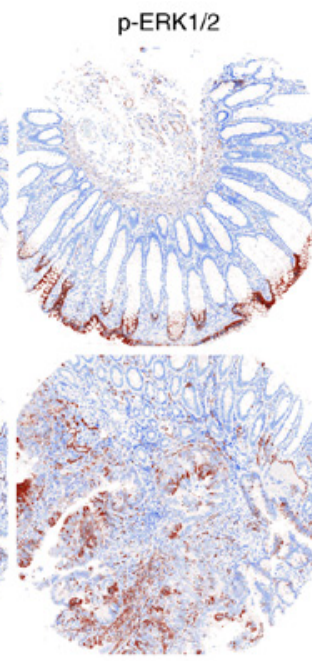

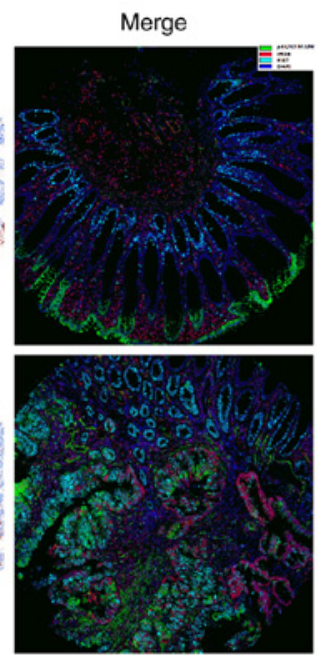
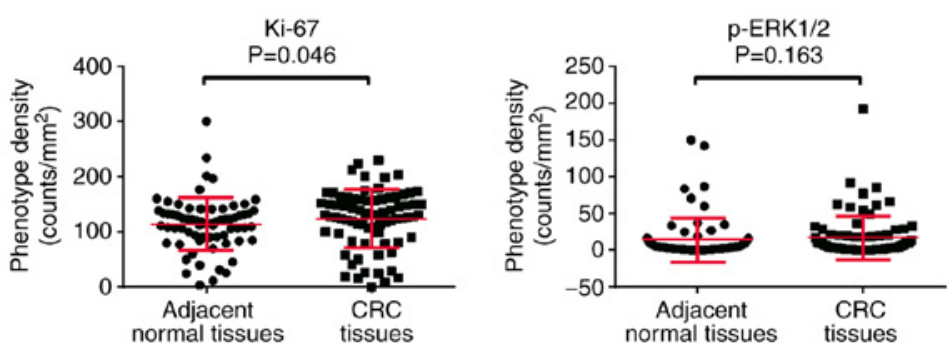

C

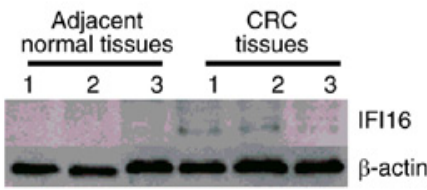

Figure 1. Differential IFI16, Ki-67 and p-ERK1/2 expression between CRC tissues and adjacent normal tissues. (A) Representative multiple-fluorophore antibody staining in CRC tissues and adjacent normal tissues from the same patient (blue, nucleus; red, IFI16; green, p-ERK1/2; and light blue, Ki-67). (B) IFI16 and Ki-67 expression was higher in CRC tissues compared with in adjacent normal tissues. However, no significant difference in p-ERK1/2 expression was observed between CRC tissue and adjacent normal tissues. Wilcoxon-signed rank tests were used to compare differences in the expression of protein variables. (C) IFI16 expression in CRC tissues and adjacent normal tissues. Whole-tissue lysate derived from tumor tissues and adjacent tissues of 3 CRC patients with CRC were collected and an equal amount of total proteins was loaded on SDS-PAGE and then subjected to western blotting to detected IFI16 expression. $\beta$-actin was used as a loading control. CRC, colorectal cancer; IFI16, interferon-induced protein 16; p, phosphorylated.

$($ Hscore $)=[($ fluorescence intensity of $1+$ cell positive rate $) \times 1+$ (fluorescence intensity of $2+$ cell positive rate) $x 2+$ (fluorescence intensity of $3+$ cell positive rate) $x 3$ ] x100.

Western blotting. Tissue lysates derived from CRC cancer tissues and paired paracancerous tissues of 3 patients with CRC were prepared using radioimunoprecipitation assay (RIPA) buffer (cat. no. P0013C; Beyotime Institute of Biotechnology) in the presence of protease inhibitor Phenylmethanesulfonyl fluoride (PFMS; cat. no. 36978; Thermo Fisher Scientific Inc.) and inhibitor cocktail (cat. no. 4693132001; Roche Diagnostics $\mathrm{GmbH}$ ). Protein concentrations of the extract tissue lysates were quantified using a bicinchoninic acid (BCA) protein assay (cat. no. P0010; Beyotime Institute of Biotechnology). A total of $10 \mu \mathrm{g}$ protein/lane was run on a $10 \%$ polyacrlamide gel under denaturing conditions. Proteins were transferred onto a PVDF membrane and blocked for $2 \mathrm{~h}$ at room temperature in $0.1 \%$ TBST with $5 \%$ skimmed milk. Subsequently the membranes were blotted with IFI16 antibodies and rabbit anti- $\beta$-actin polyclonal antibody at $4{ }^{\circ} \mathrm{C}$ overnight. The membrane was washed with TBST 3 times for 5 min each time and incubated with the horseradish peroxidise (HRP)-conjugated Affinipure Goat Anti-Rabbit IgG $(\mathrm{H}+\mathrm{L})$ secondary antibody at room temperature for $1 \mathrm{~h}$ (1:3,000; cat. no. SA00001-2, Proteintech Group Inc.). The detection was performed using Pierce ${ }^{\mathrm{TM}}$ ECL western blotting substrate (cat. no. 32106. Thermo Fisher Scientific Inc.).

Statistical analysis. SPSS v.22.0 software (IBM Corp.) was used for statistical analysis. All experiments were performed in triplicate and data are presented as the mean \pm standard deviation (SD). Differences in the means of continuous variables were compared using Wilcoxon-signed rank tests. Unpaired Student's t-tests were conducted to evaluate the association between protein expression and clinical features. Co-expression analysis of the IFI16, Ki-67, p-ERK1/2, CD8 and PD-L1 genes with clinical features was analyzed with Spearman's rank correlation. $\mathrm{P}<0.05$ was considered to indicate a statistically significant difference.

\section{Results}

Differential expression of IFI16, Ki-67 and p-ERKI/2 in CRC and adjacent tissues. To assess the expression level of IFI16 
A

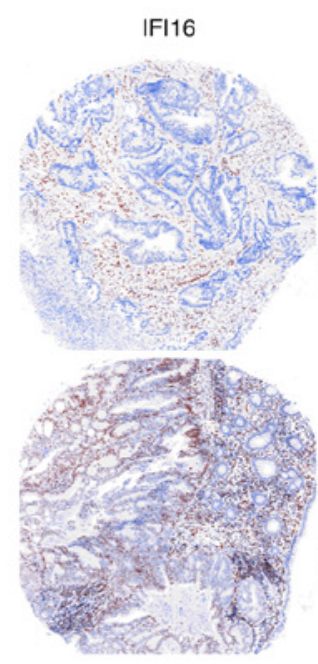

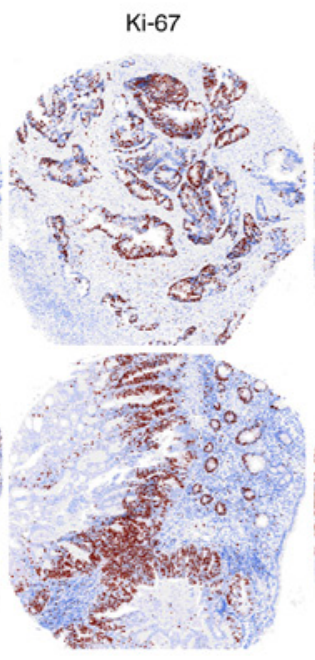
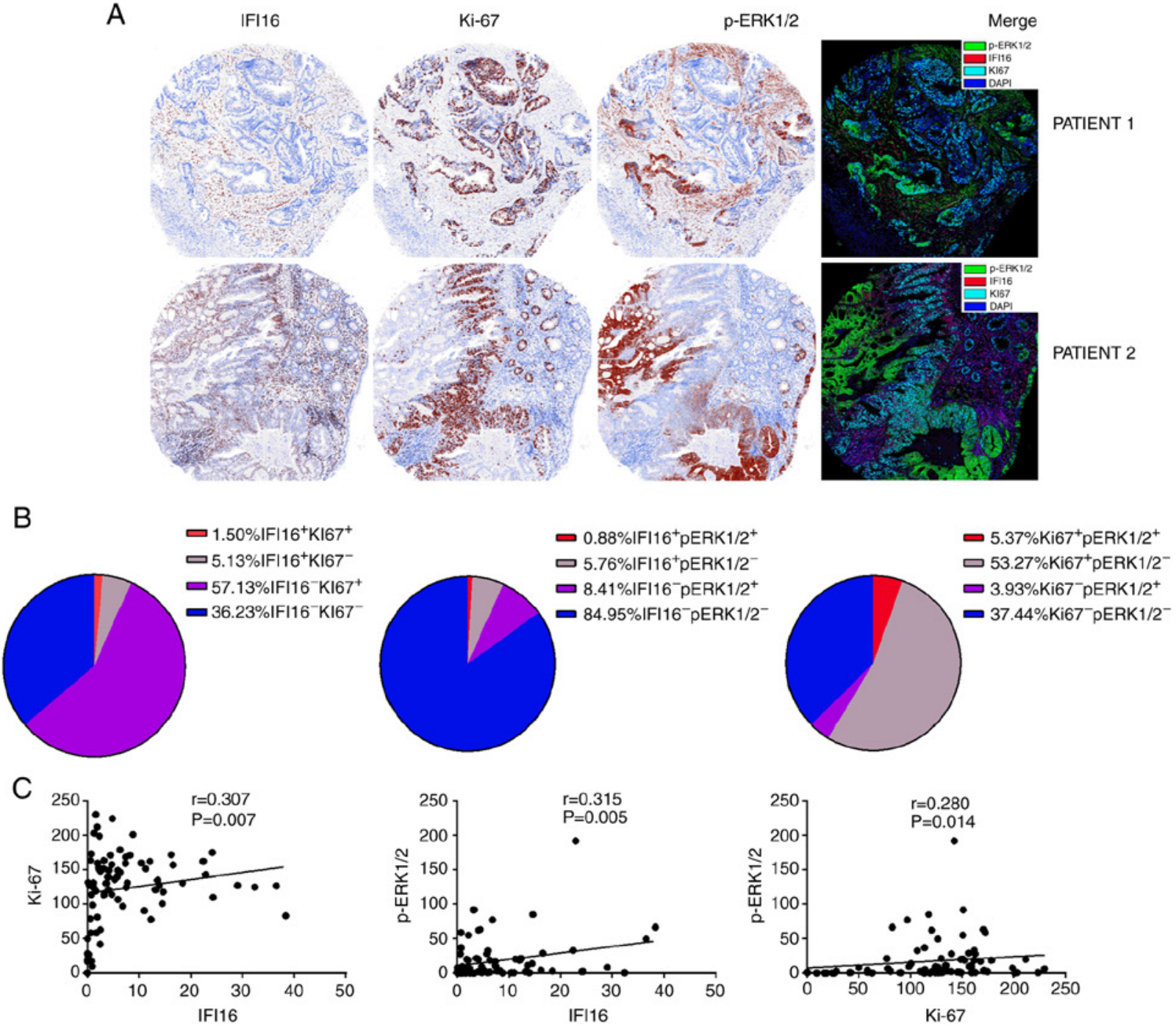

Figure 2. Co-localization of IFI16, Ki-67 and p-ERK1/2 in CRC tissues. (A) IFI16, Ki-67 and p-ERK1/2 displayed a mutually exclusive expression pattern in CRC cells. (B) The co-expression frequency of target proteins was analyzed and displayed in a pie chart. (C) IFI16 expression was significantly positively associated with Ki-67 and p-ERK1/2 expression. In addition, p-ERK1/2 was positively correlated with Ki-67 in CRC tissues. Correlations among IFI16, Ki-67 and p-ERK1/2 were evaluated with Spearman's rank correlation. CRC, colorectal cancer; IFI16, interferon-induced protein 16; p, phosphorylated.

and proliferation markers in CRC tissues and adjacent normal tissues, a multiplex immunofluorescence panel of antibodies against IFI16, Ki-67 and phosphorylated (p)-ERK1/2 was performed. Immunofluorescence assay results demonstrated that in CRC and adjacent normal tissues, IFI16 and Ki-67 were localized in the nucleus of TCs, while p-ERK1/2 was located in both the cytoplasm and the cell membrane and sometimes to the nucleus (Fig. 1A). IFI16 was highly expressed in stromal cells in both cancer and adjacent normal tissues. Although weak IFI16 expression was observed in the normal intestinal mucosal epithelial cells adjacent to cancer tissues, weak to strong IFI16 expression was observed in different CRC tissues (Fig. 1). The mean fluorescence intensity level of IFI16 protein in CRC tissues was significantly higher compared with that in normal mucosal epithelial cells adjacent to the tumour (7.48 \pm 8.84 vs. $4.38 \pm 4.93$, respectively; $\mathrm{P}=0.043$; Fig. $1 \mathrm{~B}$ ). The result was further confirmed using western blotting, although heterogeneous expression was observed as patient 3 showed very faint expression compared with the other 2 patients (Fig. 1C). Ki-67 protein was highly expressed in cancer cells in the CRC tissues, but was mainly expressed in the mucosal basal layer cells in the adjacent normal tissues (Fig. 1C). The mean fluorescence intensity level of $\mathrm{Ki}-67$ protein in cancer cells was notably higher compared with in adjacent mucosal epithelial cells $(123.35 \pm 52.42$ vs. $114.04 \pm 48.68$, respectively; $\mathrm{P}=0.046$; Fig. $1 \mathrm{~B}$ ). $\mathrm{p}$-ERK1/2 protein could be detected in both cancer cells and stromal cells in CRC tissues and was also detected in cells of adjacent normal tissues (Fig. 1A). In addition, no significant difference in the p-ERK1/2 expression was observed between CRC cells and adjacent mucosal epithelial cells $(17.29 \pm 29.70$ vs. $14.09 \pm 29.70$, respectively; $\mathrm{P}=0.163$; Fig. 1B). Taken together, these results suggested that IFI16, Ki-67 were relatively higher expressed in CRC tissues compared with normal tissues.

Co-localization and association of IFII6 with Ki-67 and p-ERK protein in CRC tissues. InForm Tissue Finder ${ }^{\mathrm{TM}}$ Advanced image analysis software was used to analysis the co-localization of the target proteins. Although, a high IFI16 level was observed in the CRC tissues of certain patients 
A

O̊

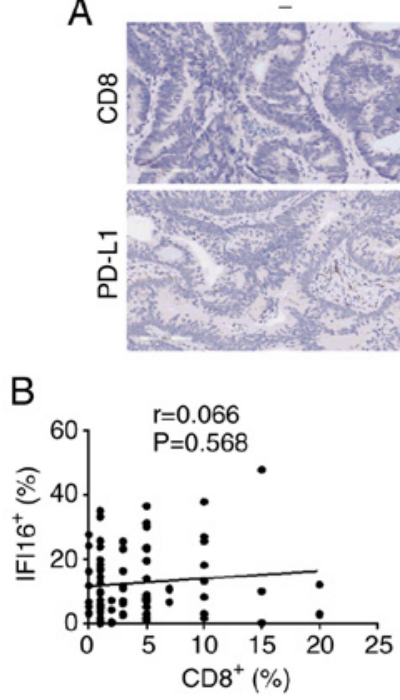

B

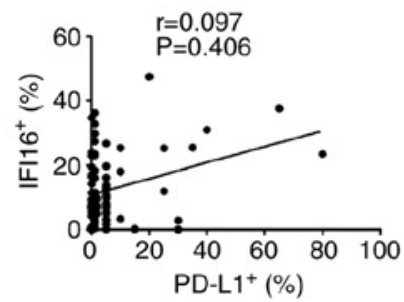

$+$
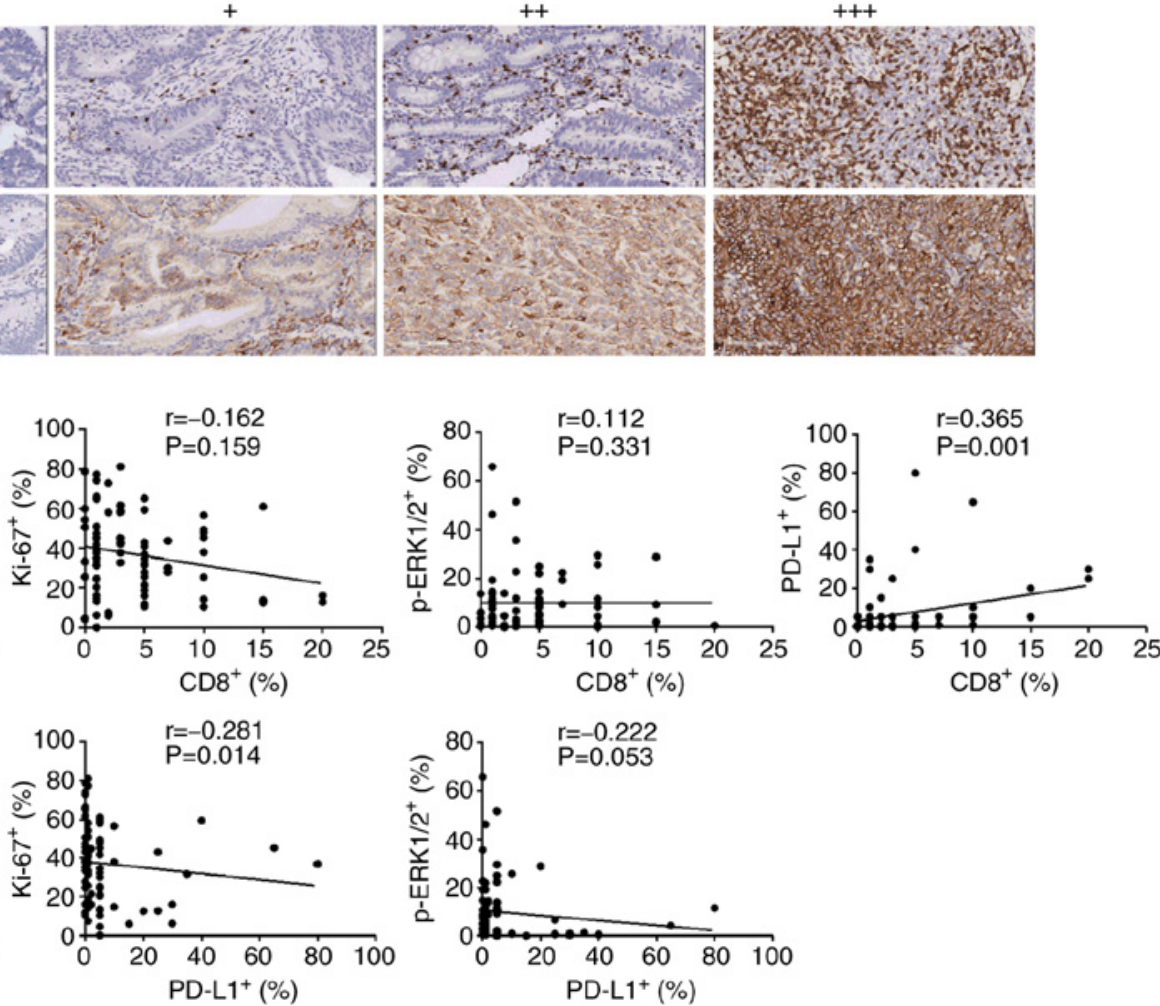

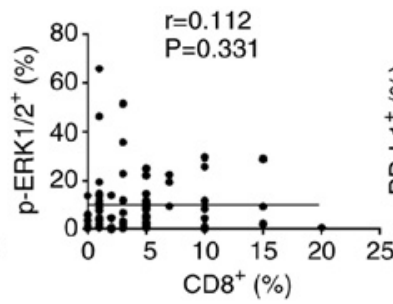

$++$
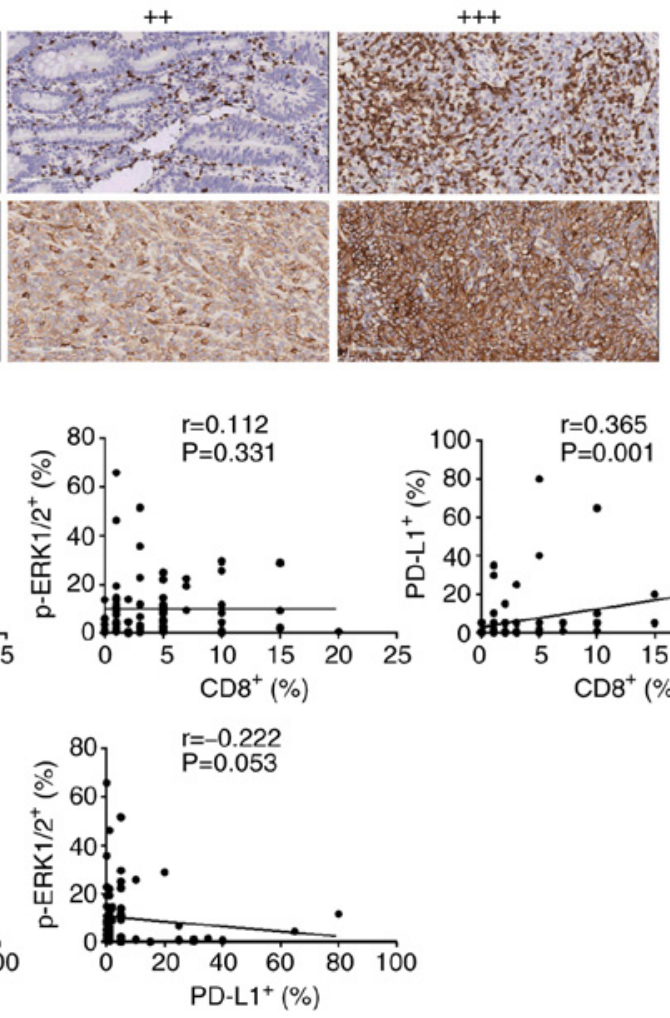

Figure 3. Imaging of CD8 ${ }^{+}$TILs and PD-L1 in CRC tissues and assessment of their correlation with IFI16, Ki-67 and p-ERK1/2. (A) A negative to strong expression level trend of CD8 ${ }^{+}$TILs and PD-L1 was displayed in the immunohistochemical image (magnification, $\left.\mathrm{x} 100\right)$. (B) Correlation between CD $8^{+} \mathrm{TILs}$ and PD-L1 with IFI16, Ki-67 and p-ERK1/2 protein expression. For CD8 ${ }^{+}$TILs, a significant positive association with PD-L1 was observed in CRC tissues. However, no significant association was observed with IFI16, Ki-67 or p-ERK1/2 protein. For PD-L1, although no significant association with IFI16 protein was observed, a significant correlation with Ki-67 and a marginal association between PD-L1 and p-ERK1/2 were observed. Correlations among IFI16, Ki-67, p-ERK1/2 with CD8 and PD-L1 were analyzed with Spearman's rank correlation. TILs, tumour infiltrating lymphocytes; PD-L1, programmed death-ligand 1; CRC, colorectal cancer; IFI16, interferon-induced protein 16; p, phosphorylated.

and the IFI16 expression level was significantly positively correlated with that of Ki-67 and p-ERK (IFI16 vs. Ki-67: $\mathrm{r}=0.307, \mathrm{P}=0.007$; IFI16 vs. $\mathrm{p}-\mathrm{ERK} 1 / 2: \mathrm{r}=0.315, \mathrm{P}=0.005)$, IFI16 was not usually co-localized with Ki-67 or p-ERK1/2 within cells (Fig. 2A and C). The proportion of double-positive cell subsets, such as $\mathrm{IFI} 16^{+} / \mathrm{Ki}-67^{+}$cells $(1.50 \%)$ or IFI $16^{+} / \mathrm{p}$-ERK $1 / 2^{+}$cells $(0.88 \%)$ was much lower compared with IFI16 single-positive cells (6.68\%) (Fig. 2B). However, the proportion of cells with mutually exclusive expression, such as IFI16 ${ }^{+} / \mathrm{Ki}-67^{-}$cells $(5.13 \%)$ and IFI16 $/ \mathrm{Ki}-67^{+}$cells $(57.13 \%)$, was much higher compared with that of the other 2 subsets (IFI16 $/ \mathrm{Ki}^{-67}{ }^{-}, 36.23 \%$; IFI16 ${ }^{+} / \mathrm{Ki}^{-67^{+}}, 1.50 \%$; Fig. 2B). In contrast to IFI16 and Ki-67 expression, the proportions of IFI16 ${ }^{+} / \mathrm{p}-\mathrm{ERK}^{-}$cell $(5.76 \%)$ and IFI16 $/ \mathrm{p}-\mathrm{ERK}^{+}$cell $(8.41 \%)$ subsets were much lower compared with that of the IFI16/p-ERK1/2 cell (84.95\%) subset (Fig. 2B). In addition, the expression level of $\mathrm{p}-\mathrm{ERK} 1 / 2$ was negligibly positively correlated with that of Ki-67 $(r=0.280$; P=0.014; Fig. $2 \mathrm{C}$ and the proportion of $\mathrm{p}$-ERK $1 / 2^{+} / \mathrm{Ki}-67^{+}$double-positive cells was only $5.37 \%$ (Fig. 2B). In addition, the proportions of cells with double-positive p-ERK $1 / 2^{+} / \mathrm{Ki}-67^{+}(5.37 \%)$, mutually exclusive expression, such as p-ERK $1 / 2^{-} / \mathrm{Ki}-67^{+}$cells $(53.27 \%)$ and $\mathrm{p}$-ERK $1 / 2^{+} / \mathrm{Ki}-67^{-}$cells $(3.93 \%)$, and double-negative cell subsets (37.44\%) displayed the same trend with IFI16 as with Ki-67 (Fig. 2B). The aforementioned results indicated that IFI16 protein in CRC tissues showed mutually exclusive expression with Ki-67 and p-ERK1/2.
CD8 and PD-L1 expression in CRC tissues and its correlation with that of IFI16, Ki-67 and p-ERK1/2 expression. To explore the association of IFI16 with immune micorenvironment of CRC cell, iimmunohistochemistry was used to test the expression of CD8 and PD-L1. It was demonstrated that in 77 CRC tissues, the mean CD8 and PD-L1 expression rates were $4.26 \pm 4.523$ and $6.86 \pm 13.849 \%$, respectively, and a significant positive correlation was observed between CD8 and PD-L1 ( $\mathrm{r}=0.365 ; \mathrm{P}=0.001$; Fig. 3B). No significant association was observed between IFI16 and CD8 or PD-L1 (IFI16 vs. CD8: $r=0.066, \mathrm{P}=0.568$; IFI16 vs. PD-L1: $\mathrm{r}=0.097, \mathrm{P}=0.406$; Fig. 3B). Although neither Ki-67 nor p-ERK1/2 expression demonstrated a significant association with CD8, a significant negative association between Ki-67 and PD-L1 and a marginally significant association between p-ERK1/2 and PD-L1 were observed (Ki-67 vs. $\mathrm{CD} 8, \mathrm{r}=0.162, \mathrm{P}=0.159$; $\mathrm{Ki}-67$ vs. PD-L1, r=-0.281, P=0.014; p-ERK1/2 vs. PD-L1, r=-0.222, $\mathrm{P}=0.053$; Fig. 3B). Collectively, these results suggested that IFI16 expression was not influenced by $\mathrm{CD}^{+} \mathrm{T}$ cells and PD-L1 expression in CRC tissues.

Association between IFI16, Ki-67, p-ERK1/2, CD8 and PD-L1 and clinical features. To further investigate clinical value of IFI16, SPSS software was used to analysis the IFI16 expression level with clinical parameters. Although IFI16 expression was significantly negatively associated with patient age (age $>55$ vs. $\leq 55,5.46 \pm 6.60$ vs. $11.69 \pm 10.55, \mathrm{P}=0.003$; Table II), no 


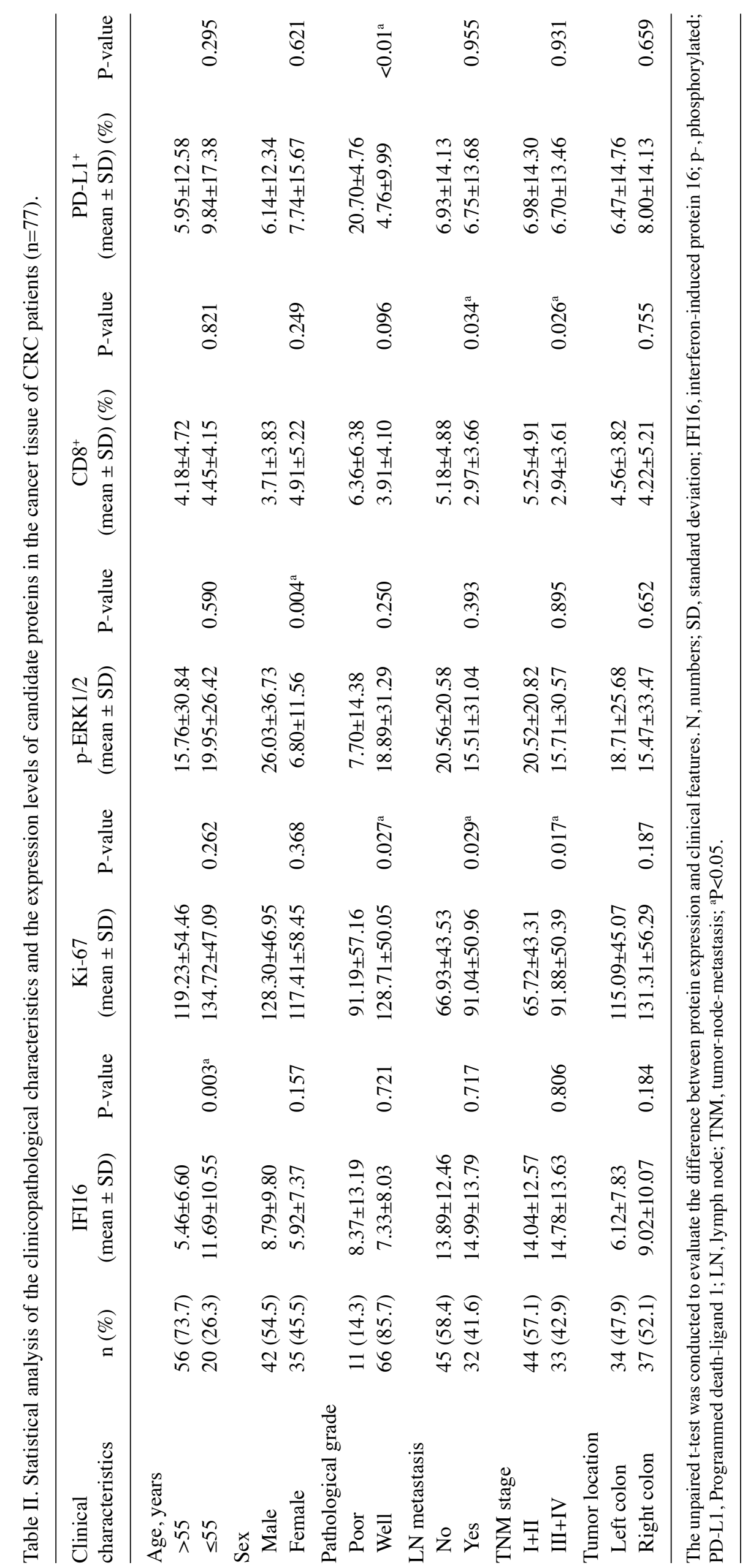

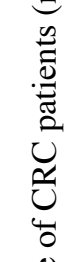


significant association was observed between IFI16 expression and tumor location, sex, pathological grade, lymph node metastasis or tumour-node-metastasis (TNM) stage (27) $(\mathrm{P}>0.05$; Table II). The cell proliferation-associated nuclear antigen Ki-67 (28) was significantly positively associated with lymph node metastasis (no vs. yes, 66.93 \pm 43.53 vs. 91.04 \pm 50.96 ; $\mathrm{P}=0.029$; Table II) and TNM stage (I+II vs. III+IV, 65.72 \pm 43.31 vs. 91.88 \pm 50.39 ; $\mathrm{P}=0.017$; Table II). The $\mathrm{p}-\mathrm{ERK} 1 / 2$ expression level was much higher in male patients compared with in female patients (male vs. female, $26.03 \pm 36.73$ vs. $6.80 \pm 11.56 ; \mathrm{P}=0.004$ ), but there was no significant association of p-ERK1/2 expression with TNM stage, lymph node metastasis, age, pathological grade and tumor location $(\mathrm{P}>0.05$; Table II). $\mathrm{CD}^{+}$tumour-infiltrating lymphocytes (TILs) were significantly negatively associated with lymph node metastasis (5.18 \pm 4.88 vs. $2.97 \pm 3.66 ; \mathrm{P}=0.034)$, $\mathrm{TNM}$ staging $(5.25 \pm 4.91$ vs. 2.94 $\pm 3.61 ; \mathrm{P}=0.026$; Table II) and positively associated with PD-L1 expression ( $\mathrm{r}=0.365$; $\mathrm{P}<0.001$; Fig. 3B). Although PD-L1 expression was negatively associated with pathological grade (poorly vs. well differentiated, $20.70 \pm 4.76$ vs. $4.76 \pm 9.99$; $\mathrm{P}<0.001$; Table II), no significant association was observed between PD-L1 and TNM stage, lymph node metastasis, age, sex and tumor location ( $\mathrm{P}>0.05$; Table II). Taken together, these results suggested that IFI16 demonstrated no significant association with clinical outcomes.

\section{Discussion}

As a natural immune recognition receptor for foreign DNA and damaged DNA, IFI16 activates the ATK/AMPK/p53 or $\mathrm{ATK} / \mathrm{IKKB} / \mathrm{NF}-\kappa \mathrm{B}$ signalling pathway and promotes cell cycle arrest or the expression of the inflammatory cytokines, such as IL-1, IL-18 and IFN- $\beta(6,7)$. The release of IFN- $\beta$ serves an important role in the body's natural immune response and in age-related cellular senescence $(6,7)$. Increased expression of IFI16 in a variety of cell types, such as human fibroblasts and bone and cartilage tumor cells promotes cell senescence (10-12). Although senescent cell are resistant to oncogenic challenge and do not proliferate, they exhibit senescence-associated secretory phenotype (SASP) (29-33). SASP is associated with secretion of proinflammatory cytokines. Senescent cells or SASP release multiple cytokines that may support the proliferation of non-senescent neighbouring cell via paracrine mechanisms. Accumulation of senescent cell or SASP in tissues or organs is thought to contribute to organismal ageing and inflammation-associated human diseases, including the development of certain cancer types, such as colon cancer and breast cancer $(34,35)$.

Increasing data have demonstrated that abnormal expression of IFI16 is closely associated with cancer development (6). Due to the different tissue sources and cell contents, IFI16 can serve a dual role as a tumour suppressor or a cancer promoter (12-21). The present study demonstrated that IFI16 expression level was very low in normal mucosal epithelial cells. However, barely detectable to strong expression was observed in CRC cells in different patients in the present study. The IFI16 expression level in CRC tissues was higher compared with in normal mucosal epithelial tissues. In addition, in the present study, a positive correlation in expression was found between IFI16 and the cell proliferation-associated nuclear antigen Ki-67. The finding of the present study suggest that IFI16 may act as an oncogene to promote CRC occurrence. However, IFI16 and Ki-67 were usually not co-localized within cells and $60 \%$ of analysed cells in the present study demonstrated mutually exclusive expression patterns. The IFI16 $/ \mathrm{Ki}-67^{+}$phenotype was significantly associated with TNM stage The results of the present study suggested that IFI16 may serve a role in inhibiting CRC cell proliferation. A potential explanation for these contradictory phenomena may be that $\mathrm{CRC}$ can be divided into 2 categories based on genomic instability: DNA repair deficiency/microsatellite instability (dMMR/MSI) and DNA repair mechanism integrity/microsatellite stability (pMMR/MSS) (36). The two tumour types show very different genetic profiles (35). dMMR/MSI tumours typically have increased tumour mutational burden, with a 100 - to 1,000-fold increased mutation rate compared with pMMR/MSS tumours (37). This high mutational rate leads to increased levels of tumour-associated antigen and immune cell infiltration $(37,38)$. We hypothesized that patients with CRC in the present study with the dMMR/MSI subtype have an even higher IFI16 expression compared with patients with CRC with pMMR/MSS tumours as a much higher gene mutational rate occurs in $\mathrm{dMMR} / \mathrm{MSI}$ tumours. Hence, it was speculated that the differential IFI16 expression in patients with CRC in the present study may be associated with the different MMR/MSI tumours present. However, increased IFI16 expression inhibits cell growth and accelerates senescence (6). To maintain tumour cells growth, the senescent cells may produce SASP to stimulate the survival and proliferation of surrounding cells $(33,35)$. At present, there are 3 main methods for detecting MMR/MSI status, including immunohistochemistry, polymerase chain reaction and second-generation sequencing (39). However, due to the scarcity of direct experimental evidence, as the TMA tissue used in the present study did not have high enough integrity to detect the MMR/MSI status, the association between IFI16, MMR/MSI status and SASP in CRC occurrence remains speculative and is a limitation of the present study.

In addition, the present study found that the IFI16 expression level was negatively associated with patient age. Compared with patients older $>55$ years, higher IFI16 levels were observed in patients younger than 55 years old. Studies by Raffaella et al and Fujiuchi et al $(13,14)$ demonstrated taht the IFI16 expression was significantly increased in old normal cells and senescent cells, and the expression was significantly downregulated with cell immortalization and malignant transformation. However, whether IFI16 expression level in malignant cells is associated with age has not yet been reported (6). In addition, sex hormones and environmental factors also influence IFI16 expression, such as prostaglandin and cervical cancer development $(6,16)$. Hence, further studies with larger sample sizes are required to verify the findings of the present study.

The present study also analysed the correlation between IFI16 and p-ERK1/2 protein. p-ERK1/2 is the phosphorylation product of ERK1/2, a downstream protein in the MAPK signalling pathway (40). The MAPK signalling pathway serves an important role in regulating cell proliferation, differentiation, migration, growth, survival and apoptosis, among other processes (41). Ras-Raf-Mek1/2-ERK1/2 is one of the important downstream cascades of the MAPK signalling pathway (42). 
When the body's proinflammatory cytokines bind to receptors on the cell surface, the MAPK signalling pathway is activated to promote cell growth, proliferation, differentiation or apoptosis, such as tumor necrosis factor- $\alpha$ (TNF $\alpha)$ (37). Previous studies have demonstrated that IFI16 is involved in Ras signalling pathway activation (43-45). Kim et al (45) demonstrated that in the occurrence of thyroid cancer, IFI16 acts as a downstream regulator in the RAS/RAF/ERK signalling pathway to inhibit the continuous activation of cells induced by the Ras oncogene. In 2010, Lengyel et al (46) demonstrated that the p204 protein (a mouse family member homologous to the IFI16 protein) is an important protein that regulates Ras and its downstream signalling pathways. Hence, the correlation between IFI16 and p-ERK1/2 was investigated in the present study. The present study revealed that p-ERK1/2 was located mainly in the cytoplasm and cell membrane rather than the nucleus. Although the IFI16 expression level was significantly positively correlated with that of p-ERK1/2, the co-localization rate of IFI16 and p-ERK $1 / 2$ in the same cell was very low $(0.88 \%)$, and $\sim 84.95 \%$ of the analysed cells were double-negative for IFI16 and p-ERK1/2. The IFI16 and p-ERK1/2 expression model was quite different from that of IFI16 and Ki-67 observed in the present study. Surprisingly, only $5.86 \%$ of the analysed cells showed a p-ERK $1 / 2^{+} / \mathrm{Ki}-67^{+}$phenotype, and $57.2 \%$ of the analysed cells showed a mutually exclusive expression phenotype, such as p-ERK1/2 $/ \mathrm{Ki}-67^{+}$or p-ERK1/2 $/ \mathrm{Ki}-67^{-}$. In addition, patients with the $\mathrm{p}$-ERK1/2- $/ \mathrm{Ki}-67^{+}$phenotype had more lymph node migration and a more advanced TNM stage and the opposite was observed in patients with the p-ERK1/2+/Ki-67 phenotype in the present study. These results suggested that p-ERK1/2, similar to IFI16, may serve a role in inhibiting CRC cell proliferation.

p-ERK $1 / 2$ is located in the cytoplasm and subsequently translocates to the nucleus, where it activates transcription factors, such as c-Jun and Fos (40). Nuclear translocation of ERK/MAPK is required for mitogenesis (46). Cytosolic retention of $\mathrm{p}$-ERK1/2 can activate certain proapoptotic proteins, such as cytosolic death-associated protein kinase 1 (47). The nucleocytoplasmic distribution of ERK/MAPK is used for regulating ERK/MAPK signalling (48). There are quite a few proteins involved in the regulation of localizing ERK/MAPK signalling, such as LYN proto-oncogene (Lyn), proliferation and apoptosis adaptor protein 15 (PEA15) and human Sef gene (46-48). Our present data indicated that p-ERK1/2 is expressed in both the membrane and cytoplasm of CRC cells and in the nucleus. p-ERK1/2 expression was also positively correlated with Ki-67 protein expression. These results indicated that the p-ERK1/2 expression level was closely associated with the proliferation potential of CRC cells, which is consistent with the aforementioned studies (49-51). However, the results of the present study demonstrated that p-ERK1/2 does not usually co-localize with Ki-67 in CRC cells, which contradicted the aforementioned results. The inconsistent results may be partially due to the inability to divide the p-ERK1/2 protein into nuclear-located p-ERK1/2 and non-nuclear located ERK1/2 and analyse the subsets separately in the present study. Hence, future studies should clarify this issue using in vitro cell culture experiments.

In addition, the present study demonstrated that the p-ERK1/2 expression level in males was much higher compared with in females. We hypothesised that this result may be associated with the samples used in the present study. p-ERK $1 / 2$ expression is affected by numerous factors, such as hypoxia and chronic inflammation and thus, whether there is a direct correlation between p-ERK1/2 and sex in CRC tissues must be further verified in future studies.

IFI16 is an important protein that links innate immunity and adaptive immunity (7). Intracellular DNA activation of human monocyte-derived dendritic cells (DCs) as well as primary DCs was dependent upon IFI16 protein expression and IFN- $\beta$ expression (52). More important, activated DCs induce naive $\mathrm{CD} 4^{+} \mathrm{T}$ cells to promote Th1-type cytokine production, such as IL-2, IFN- $\gamma(53)$ and generate $\mathrm{CD} 4^{+}$and $\mathrm{CD} 8^{+}$cytotoxic T cells (54). Qi et al (55) reported that IFI16 expression may be a good prognostic biomarker and immunotherapeutic target in patients with HCC. Hence, the present study detected and analysed the relationship between IFI16 expression and PD-L1/CD8 ${ }^{+}$TILs in CRC tissues. However as the findings of the present study demonstrated no significant association was observed between IFI16 and CD8 ${ }^{+}$TILs or PD-L1 expression. This result was opposite of that by Cai et al (16), who demonstrated that IFI16 promotes cervical cancer progression by upregulating PD-L1 expression. This difference may be attributed to differences in the diseases or the methods. In addition, the present study did not subtype the patients with CRC based on molecular characteristics, such as MMR/MSI phenotype, which may influence the expression model obtained for IFI16, PD-L1 and CD8 ${ }^{+}$TIL.

CD8 ${ }^{+}$TIL infiltration was positively associated with PD-L1 expression in the present study. Infiltration of CD8 ${ }^{+}$ TILs boosts PD-L1 expression in cancer cells to facilitate their escape from attack by CD8 ${ }^{+}$TILs (56-59). Therefore, the findings of the present study also supported the notion that the expression level of PD-L1 in CRC tissues can be used as an effective predictor of the response to the programmed death/PD-L1 immune checkpoint therapy. CD8 ${ }^{+}$TIL infiltration in CRC tissues was related to a low rate of lymph node metastasis and early TNM stage in the present study, which further supports the notion that CD8 ${ }^{+} \mathrm{TIL}$ abundance is a good predictor of clinical outcome for patients with CRC $(60,61)$. In conclusion, to the best of our knowledge, the present study was the first time multiplex immunofluorescence and IHC techniques were used to explore the expression and potential mechanism of IFI16 in CRC tissues. Although IFI16 expression was significantly increased in CRC tissues compared with adjacent normal tissues and had a positive association with Ki-67 and p-ERK1/2 expression, IFI16 usually showed mutually exclusive expression patterns with Ki-67 p-ERK1/2. The findings of the present study suggested that increased IFI16 expression may serve a role in inhibiting CRC cell proliferation and contribute to cell senescence. In addition, the senescent cells likely stimulate the survival and proliferation of surrounding cells through production of SASP. However, future studies need to be conducted to support this hypothesis and uncover the molecular mechanism underlying IFI16 in CRC occurrence.

\section{Acknowledgements}

Not applicable. 


\section{Funding}

The present study was supported by the Health Bureau of Yunnan Province (grant nos. 2017NS226 and 2018NS0247); the Yunnan Digestive Endoscopy Clinical Medical Center Foundation for Health Commission of Yunnan Province (grant no. 2019LCZXKF-XH04); the Yunnan Blood Disease Clinical Medical Center Foundation for Health Commission of Yunnan Province (grant no. 2020LCZXKF-XY08); and in part by the Science and Technology Department of Yunnan Province (grant no. 2018DG010).

\section{Availability of data and materials}

The datasets used and/or analyzed during the current study are available from the corresponding author on reasonable request.

\section{Authors' contributions}

YZ and XY designed the study and wrote the manuscript. JZ and LZ performed the experiments and collected the data. $\mathrm{YZ}$ and $\mathrm{XY}$ analysed and interpreted the data. YL and $\mathrm{XY}$ confirmed the authenticity of all the raw data. All the authors have read and approved the final manuscript.

\section{Ethics approval and consent to participate}

All participants provided written informed consent, and the study was approved by the Ethics Committee of the First People's Hospital of Yunnan Province (Kunming, China).

\section{Patient consent for publication}

Not applicable.

\section{Competing interests}

The authors declare that they have no competing interests.

\section{References}

1. Dekker E, Tanis PJ, Vleugels J, Kasi PM and Wallace MB: Colorectal cancer. Lancet 394: 1467-1480, 2019.

2. Siegel RL, Miller KD, Goding Sauer A, Fedewa SA, Butterly LF, Anderson JC, Cercek A, Smith RA and Jemal A: Colorectal cancer statistics, 2020. CA Cancer J Clin 70: 145-164, 2020.

3. Dawson MJ and Trapani JA: IFI 16 gene encodes a nuclear protein whose expression is induced by interferons in human myeloid leukaemia cell lines. J Cell Biochem 57: 39-51, 1995.

4. Wei W, Clarke CJ, Somers GR, Cresswell KS, Loveland KA, Trapani JA and Johnstone RW: Expression of IFI16 in epithelial cells and lymphoid tissues. Histochem Cell Biol 119: 45-54, 2003.

5. Stehlik C: The PYRIN domain in signal transduction. Curr Protein Pept Sci 8: 293-310, 2007.

6. Choubey D and Panchanathan R: IFI16, an amplifier of DNA-damage response: Role in cellular senescence and aging-associated inflammatory diseases. Ageing Res Rev 28: 27-36, 2016.

7. Lin $\mathrm{H}$ and Cao X: Nuclear innate sensors for nucleic acids in immunity and inflammation. Immunol Rev 297: 162-173, 2020.

8. Pancanathan R, Liu H, Leung YK, Ho SM and Choubey D: Bisphenol A (BPA) stimulates the interferon signaling and activates the inflammasome activity in meloid cells. Mol Cell Endocrinol 415: 45-55, 2015.
9. Cui J, Chen Y, Wang HY and Wang RF: Mechanisms and pathways of innate immune activation and regulation in health and cancer. Hum Vaccin Immunother 10: 3270-3285, 2014.

10. Ouchi M and Ouchi T: Role of IFI16 in DNA damage and checkpoint. Front Biosci 13: 236-239, 2008.

11. Duan X, Ponomareva L, Veeranki S and Choubey D: IFI16 induction by glucose restriction in human fibroblasts contributes to autophagy through activation of the ATM/AMPK/p53 pathway. PLoS One 6: e19532, 2011.

12. Zhang Y, Howell RD, Alfonso DT, Yu J, Kong L, Wittig JC and Liu CJ: IFI16 inhibits tumorigenicity and cell proliferation of bone and cartilage tumor cells. Front Biosci 12: 4855-4863, 2007.

13. Raffaella R, Gioia, D, De Andrea M, Cappello P, Giovarelli M, Marconi P, Manservigi R, Gariglio M and Landolfo S: The interferon-inducible IFI16 gene inhibits tube morphogenesis and proliferation of primary, but not HPV16 E6/E7 immortalized human endothelial cells. Exp Cell Res 293: 331-345, 2004.

14. Fujiuchi N, Aglipay JA, Ohtsuka T, Maehara N, Sahin F, Su GH, Lee SW and Ouchi T: Requirement of IFI16 for the maximal activation of $\mathrm{p} 53$ induced by ionizing radiation. J Biol Chem 279: 20339-20344, 2004.

15. Alimirah F, Chen J, Davis FJ and Choubey D: IFI16 in human prostate cancer. Mol Cancer Res 5: 251-259, 2007.

16. Cai H, Yan L, Liu N, Xu M and Cai H: IFI16 promotes cervical cancer progression by upregulating PD-L1 in immunomicroenvironment through STING-TBK1-NF- $\kappa$ B pathway. Biomed Pharmacother 123: 109790, 2020.

17. Kim MK, Mason JM, Li CM, Berkofsky-Fessler W, Jiang L, Choubey D, Grundy PE, Tycko B and Licht JD: A pathologic link between Wilms tumor suppressor gene, WT1, and IFI16. Neoplasia 10: 69-78, 2008.

18. Yu F, Hao X, Zhao H, Ge C, Yao M, Yang S and Li J: Delta-like 1 contributes to cell growth by increasing the interferon-inducible protein 16 expression in hepatocellular carcinoma. Liver Int 30: 703-714, 2010.

19. Shi XL, Yang J, Mao N, Wu JH, Ren LF, Yang Y, Yin XL, Wei L, Li MY and Wang BN: Nutlin-3-induced redistribution of chromatin-bound IFI16 in human hepatocellular carcinoma cells in vitro is associated with p53 activation. Acta Pharmacol Sin 36: 252-258, 2015.

20. Shi X, Liu J, Liu Q and Li M: IFI16 mis-localization can be a contributing factor to hepatocellular carcinoma progression. Med Hypotheses 82: 398-400, 2014.

21. Tang H, Guo Q, Zhang C, Zhu J, Yang H, Zou YL, Yan Y, Hong D, Shou T and Yan XM: Identification of an intermediate signature that marks the initial phases of the colorectal adenoma-carcinoma transition. Int J Mol Med 26: 631-641, 2010.

22. Yang CA, Huang HY, Chang YS, Lin CL, Lai IL and Chang JG: DNA-Sensing and nuclease gene expressions as markers for colorectal cancer progression. Oncology 92: 115-124, 2017.

23. Turkington CJR, Varadan AC, Grenier SF and Grasis JA: The viral Janus: Viruses as aetiological agents and treatment options in colorectal cancer. Front Cell Infect Microbiol 10: 601573, 2020.

24. Torlakovic EE, Nielsen S, Francis G, Garratt J, Gilks B, Goldsmith JD, Hornick JL, Hyjek E, Ibrahim M, Miller K, et al: Standardization of positive controls in diagnostic immunohistochemistry: Recommendations from the international Ad Hoc Expert Committee. Appl Immunohistochem Mol Morphol 23: 1-18, 2015.

25. Skaland I, Nordhus M, Gudlaugsson E, Klos J, Kjellevold KH, Janssen EA and Baak JP: Evaluation of 5 different labeled polymer immunohistochemical detection systems. Appl Immunohistochem Mol Morphol 18: 90-96, 2010.

26. Muto T, Bussey HJ and Morson BC: The evolution of cancer of the colon and rectum. Cancer 36: 2251-2270, 1975.

27. Greene FL: Current TNM staging of colorectal cancer. Lancet Oncol 8: 572-573, 2007.

28. Li LT, Jiang G, Chen Q and Zheng JN: Ki67 is a promising molecular target in the diagnosis of cancer (review). Mol Med Rep 11: 1566-1572, 2015.

29. Piccaluga PP, Agostinelli C, Righi S, Ciccone M, Re MC, Musumeci G, Diani E, Signoretto C, Bon L, Piccin O, et al: IFI16 reduced expression is correlated with unfavorable outcome in chronic lymphocytic leukemia. APMIS 125: 511-522, 2017.

30. Man SM, Karki R and Kanneganti T: DNA-sensing inflammasomes: Regulation of bacterial host defense and the gut microbiota. Pathog Dis 74: ftw28, 2016.

31. Veeranki S and Choubey D: Systemic lupus erythematosus and increased risk to develop B cell malignancies: Role of the p200-family proteins. Immunol Lett 133: 1-5, 2010. 
32. Salama R, Sadaie M, Hoare M and Narita M: Cellular senescence and its effector programs. Genes Dev 28: 99-144, 2011.

33. Sharpless NE and Sherr CJ: Forging a signature of in vivo senescence. Nat Rev Cancer 15: 397-408, 2015.

34. Guo Y, Ayers JL, Carter KT, Wang T, Maden SK, Edmond D, Newcomb PP, Li C, Ulrich C, Yu M and Grady WM: Senescence-associated tissue microenvironment promotes colon cancer formation through the secretory factor GDF15. Aging Cell 18: e13013, 2019.

35. Demaria M, Q'Leary MN, Chang J, Shao L, Liu S, Alimirah F, Koening K, Le C, Mitin N, Deal AM, et al: Cellular senescence promotes adverse effects of chemotherapy and cancer relapse. Dancer Dissov 7: 165-176, 2017.

36. Lai E, Liscia N, Donisi C, Mariani S, Tolu S, Pretta A, Persano M, Pinna G, Balconi F, Pireddu A, et al: Molecular-Biology-Driven treatment for metastatic colorectal cancer. Cancers (Basel) 12: $1214,2020$.

37. Le DT, Uram JN, Wang $H$, Bartlett BR, Kemberling $H$, Eyring AD, Skora AD, Luber BS, Azad NS, Laheru D, et al: PD-1 blockade in tumors with mismatch-repair deficiency. N Engl J Med 372: 2509-2520, 2015.

38. Lizardo DY, Kuang C, Hao S, Yu J, Huang Y and Zhang L: Immunotherapy efficacy on mismatch repair-deficient colorectal cancer: From bench to bedside. Biochim Biophys Acta Rev Cancer 1874: 188447, 2020

39. Evrard C, Tachon G, Randrian V, Karayan-Tapon L and Tougeron D: Microsatellite instability: Diagnosis, heterogeneity, discordance, and clinical impact in colorectal cancer. Cancers (Basel) 11: 1567, 2019.

40. Keshet Y and Seger R: The MAP kinase signaling cascades: A system of hundreds of components regulates a diverse array of physiological functions. Mothods Mol Biol 661: 3-38, 2010.

41. Sun Y, Liu WZ, Liu T, Feng X, Yang N and Zhou HF: Signaling pathway of MAPK/ERK in cell proliferation, differentiation, migration, senescence and apoptosis. J Recept Signal Transduct Res 35: 600-604, 2015.

42. Ye Q, Cai W, Zheng Y, Evers BM and She QB: ERK and AKT signaling cooperate to translationally regulate survivin expression for metastatic progression of colorectal cancer. Oncogene 33: $1828-1839,2014$.

43. Ding B and Lengyel P: p204 protein is a novel modulator of ras activity. J Biol Chem 283: 5831-5848, 2008.

44. Luan Y, Lengyel P and Liu CJ: p204, a p200 family protein, as a multifunctional regulator of cell proliferation and differentiation. Cytokine Growth Factor Rev 19: 357-369, 2008.

45. Kim EJ, Park JI and Nelkin BD: IFI16 is an essential mediator of growth inhibition, but not differentiation, induced by the leukemia inhibitory factor/JAK/STAT pathway in medullary thyroid carcinoma cells. J Biol Chem 280: 4913-4920, 2005.

46. Lengyel P and Liu CJ: The p200 family protein p204 as a modulator of cell proliferation and differentiation: A brief survey. Cell Mol Life Sci 67: 335-340, 2010.

47. Kolc W: Coordinating ERK/MAPK signalling through scaffolds and inhibitors. Nat Rev Mol Cell Biol 6: 827-837, 2005.

48. Brunet A, Roux D, Lenormand P, Dowd S, Keyse S and Pouysségur J: Nuclear translocation of p42/p44 mitogen-activated protein kinase is required for growth factor-induced gene expression and cell cycle entry. EMBO J 18: 664-674, 1999.

49. Su N, Peng L, Xia B, Zhao Y, Xu A, Wang J, Wang X and Jiang B: Lyn is involved in CD24-induced ERK1/2 activation in colorectal cancer. Mol Cancer 11: 43, 2012.
50. Whitehurst AW, Robinson FL, Moore MS and Cobb M: The death effector domain protein PEA-15 prevents nuclear entry of ERK2 by inhibiting required interactions. J Biol Chem 279 : 12840-12847, 2004

51. Torii S, Kusakabe M, Yamamoto T, Maekawa M and Nishida E: Sef is a spatial regulator forr Ras/MAP kinase signaling. Dev Cell 7: 33-44, 2004.

52. Gil-Jaramillo N, Rocha AP, Raiol T, Motta FN, Favali C, Brigido MM, Bastos IMD and Santana JM: Trypanosoma cruzi The First Contact of human Dendritic cells with reveals response to virus as an unexplored central pathway. Front Immunol 12: 638020,2021

53. Lu N and Malemud CJ: Extracellular signal-regulated Kinase: A regulator of cell growth, inflammation, chondrocyte and bone cell receptor-mediated gene expression. Int J Mol Sci 20: 3792, 2019.

54. Kis-Toth K, Szanto A, Thai TH and Tsokos GC: Cytosolic DNA-activated human dendritic cells are potent activators of the adaptive immune response. J Immunol 187: 1222-1234, 2011.

55. Qi Z, Yan F, Chen D, Xing W, Li Q, Zeng W, Bi B and Xie J: Identification of prognostic biomarkers and correlations with immune infiltrates among Cgas-STING in hepatocellular carcinoma. Biosci Rep 40: BSR20202603, 2020.

56. Galon J, Costes A, Sanchez-Cabo F, Kirilovsky A, Mlecnik B, Lagorce-pages C, Tosolini M, Camus M, Berger A, Wind P, et al: Type, density, and location of immune cells within human colorectal tumors predict clinical outcome. Science 313: 1960-1964, 2006

57. Mlecnik B, Tosolini M, Kirilovsky A, Berger A, Bindea G, Meatchi T, Bruneval P, Trajanoski Z, Fridman WH, Pagès F and Galon J: Histopathologic-based prognostic factors of colorectal cancers are associated with the state of the local immune reaction. J Clin Oncol 29: 610-618, 2011.

58. Payandeh Z, Khalili S, Somi M, Mard-Soltani M Baghbanzadeh A, Hajiasgharzadeh K, Samadi N and Baradaran B: PD-1/PD-L1-dependent immune response in colorectal cancer. J Cell Physiol 235: 5461-5475, 2020.

59. Peng QH, Wang CH, Chen HM, Zhang RX, Pan ZZ, Lu ZH, Wang GY, Yue X, Huang W and Liu RY: CMTM6 and PD-L1 coexpression is associated with an active immune microenvironment and a favorable prognosis in colorectal cancer. J Immunother Cancer 9: e001638, 2021.

60. Akiyoshi T, Gotoh O, Tanaka N, Kiyotani K, Yamamoto N, Ueno M, Fukunaga Y and Mori S: T-cell complexity and density are associated with sensitivity to neoadjuvant chemoradiotherapy in patients with rectal cancer. Cancer Immunol Immunother 70: 509-518, 2021.

61. Kikuchi T, Mimura K, Okayama H, Nakayama Y, Saito K, Yamada L, Endo E, Sakamoto W, Fujita S, Endo H, et al: A subset of patients with MSS/MSI-low-colorectal cancer showed increased CD8(+) TILs together with up-regulated IFN- $\gamma$. Oncol Lett 18: 5977-5985, 2019.

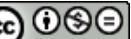

This work is licensed under a Creative Commons Attribution-NonCommercial-NoDerivatives 4.0 International (CC BY-NC-ND 4.0) License. 